\title{
Getting Closer to Our Unpleasant Previse: Possible Rise in Suicide Rate in Iran During COVID-19 Pandemic
}

\author{
Sara Nooraeen ${ }^{1}$, Maryam Javanbakht ${ }^{1}$ and Seyed Kazem Malakouti ${ }^{1,{ }^{*}}$ \\ ${ }^{1}$ Mental Health Research Center, School of Behavioral Sciences and Mental Health, Iran University of Medical Sciences, Tehran, Iran \\ "Corresponding author: Mental Health Research Center, School of Behavioral Sciences and Mental Health, Iran University of Medical Sciences, Tehran, Iran. Email: \\ malakouti.k@iums.ac.ir
}

Received 2020 December 15; Accepted 2020 December 17.

Keywords: COVID-19, Iran, Suicide

\section{Dear Editor,}

The novel coronavirus 2019 (COVID-19) has expanded rapidly around the world. In addition to physical illness, COVID-19 has affected other aspects of human life in a variety of ways. Because of its high transmission and mortality rate and the absence of effective treatment and vaccine, governments have implemented social distancing, isolation, quarantine, and lockdowns in society. Now the world is facing the third wave of soaring death tolls from COVID19. It has led to the closure of many businesses, and millions of people have lost their jobs. Financial problems, especially in developing countries, became one of the important consequences of this contagious disease. These conditions, in combination with the psychological burdens of quarantine and lockdown, may cause mental health problems such as fear, stress, anxiety, depression, PTSD, and unresolved grief and suicide (1). Some case-series and report studies of COVID-19-related suicides have been reported in different countries, hitherto $(2,3)$. One case of COVID-19related family suicide in Iran has been reported after the death of the father due to COVID-19 (4). Other suicide cases related to COVID-19 have been reported in the media. For instance, a 36-year-old woman in Tehran, the capital city, with no record of personal/family history of psychiatric illness or attempted suicide, committed suicide during the period of quarantine. This suicide happened after two months of her husband's infection with COVID-19. She became depressed and committed suicide by jumping off the sixth floor of a residential building (5). Another case of an 86-year-old man in Tabriz with an unknown psychiatric history was hospitalized due to complications from Covid-19, attempted suicide by jumping from his hospital room (6).

A recent study demonstrated that the loss of jobs due to COVID-19 could lead to between 2,135 and 9,570 suicides per year worldwide (7). According to the Islamic Parliament Research Center, in Iran, the current pandemic will lead to the loss of jobs for 2.9 to 6.4 million people (8). In Iran, a psychological autopsy study reported that unemployment increases the suicide rate by a factor of 6 (9).

Our concern is the future growth of suicide rates, especially in Post-COVID-19 times. Psychological distress, psychiatric disorders, and suicide rates could increase after a crisis such as natural disasters or economic recessions (10, 11). Alongside other studies, which did not show increases in the suicide rate during the COVID-19 pandemic (12), registered data of the Ministry of health indicated that during the first six months since the beginning of COVID-19 in Iran, the rate of suicide and suicide attempts has not increased from the corresponding date of last year. Surprisingly, this trend was on the rise in September 2020 remarkably with unknown reasons thus far (13). Does it mean that the socioeconomic effect of COVID-19 is going to gradually reveal its detrimental effect on the mental health of our society and the increasing rate of suicide? Now we are in the third wave of soaring death tolls from COVID-19, and alongside other countries, partial and total lockdowns may be imposed, with great economic pressure, particularly on deprived people. The health system has to be conscious of and set the stage for all possibilities to trace critical suicidal behavior in real-time and tackle the predictable rate increase of suicidal behaviors.

\section{Footnotes}

Authors' Contribution: Study concept and design: Seyed Kazem Malakouti. Acquisition of data: Sara Nooraeen. Drafting of the manuscript: Maryam Javanbakht. Study supervision: Seyed Kazem Malakouti. 
Conflict of Interests: The authors have no competing or conflicting interest to declare.

\section{Funding/Support: None.}

\section{References}

1. Gunnell D, Appleby L, Arensman E, Hawton K, John A, Kapur N, et al. Suicide risk and prevention during the COVID-19 pandemic. Lancet Psychiatry. 2020;7(6):468-71. doi: 10.1016/S2215-0366(20)30171-1. [PubMed: 32330430]. [PubMed Central: PMC7173821].

2. Mamun MA, Griffiths MD. First COVID-19 suicide case in Bangladesh due to fear of COVID-19 and xenophobia: Possible suicide prevention strategies. Asian J Psychiatr. 2020;51:102073. doi: 10.1016/j.ajp.2020.102073. [PubMed: 32278889]. [PubMed Central: PMC7139250].

3. Goyal K, Chauhan P, Chhikara K, Gupta P, Singh MP. Fear of COVID 2019: First suicidal case in India !. Asian J Psychiatr. 2020;49:101989. doi: 10.1016/j.ajp.2020.101989. [PubMed: 32143142]. [PubMed Central: PMC7130010].

4. Pirnia B, Dezhakam H, Pirnia K, Malekanmehr P, Rezaeian M. Grief of COVID-19 is a mental contagion, first family suicide in Iran. Asian J Psychiatr. 2020;54:102340. doi: 10.1016/j.ajp.2020.102340. [PubMed: 32777756]. [PubMed Central: PMC7834061].

5. Young Woman Suicide Due to Covid-19. Emerg Infect Dis. 2020, [cited 2020 May 17]. Available from: https://www.hamshahrionline.ir/news/ 512297.
6. Covid-19 patient Suicide in Emam Reza Hospital in Tabriz. 2020, [cited 2020 Oct 13]. Available from: https://www.rokna.net/fa/tiny/news616257.

7. Oyesanya M, Lopez-Morinigo J, Dutta R. Systematic review of suicide in economic recession. World J Psychiatry. 2015;5(2):243-54. doi: 10.5498/wjp.v5.i2.243. [PubMed: 26110126]. [PubMed Central: PMC4473496].

8. Unemployment of 2.9 to 6.4 million Iranians due to the Covid-19, Explain 7 effective global measures to reduce the living consequences of the corona Damage to 4.8 million jobs due to the virus. Ilna news; 2020, [cited 2020 Aug 5]. Available from: https://www.ilna.news/fa/tiny/news-954634

9. Rasouli N, Malakouti SK, Rezaeian M, Saberi SM, Nojomi M, De Leo D, et al. Risk Factors of Suicide Death Based on Psychological Autopsy Method; a Case-Control Study. Arch Acad Emerg Med. 2020;7(1). e50.

10. Safarpour H, Sohrabizadeh S, Malekyan L, Safi-Keykaleh M, Pirani D, Daliri S, et al. Suicide Death Rate after Disasters: A Meta-Analysis Study. Arch Suicide Res. 2020:1-14. doi: 10.1080/13811118.2020.1793045. [PubMed: 32674715].

11. Devitt P. Can we expect an increased suicide rate due to Covid-19? Ir J Psychol Med. 2020;37(4):264-8. doi: 10.1017/ipm.2020.46. [PubMed: 32434598]. [PubMed Central: PMC7287306].

12. John A, Okolie C, Eyles E, Webb RT, Schmidt L, McGuiness LA, et al. The impact of the COVID-19 pandemic on self-harm and suicidal behaviour: a living systematic review. F1000Research. 2020;9. doi: 10.12688/f1000research.25522.1.

13. Meeting of the Academy of Medical Sciences, Islamic Republic of Iran. The Representative of Iranian Legal Medicine Organization; 2020. 